\title{
Communication and Leadership Skills: A Comparative Study of the Malay Language Specialization Trainee Teachers in Malaysia
}

\author{
Nur Ehsan Mohd Said ${ }^{1}$, Zamri Mahamod ${ }^{1} \&$ Anisah Alias ${ }^{1}$ \\ ${ }^{1}$ Faculty of Education, Universiti Kebangsaan Malaysia, Selangor, Malaysia \\ Correspondence: Nur Ehsan Mohd Said, Faculty of Education, Universiti Kebangsaan Malaysia, 43600 UKM \\ Bangi, Selangor, Malaysia Tel: 60-3-8921-7687 E-mail: nurehsan@yahoo.com
}

\author{
Received: August 16, 2013 Accepted: October 14, 2013 Online Published: November 28, 2013 \\ doi:10.5539/ass.v9n16p142 URL: http://dx.doi.org/10.5539/ass.v9n16p142
}

\begin{abstract}
This research was conducted to compare generic skills involving the Malay language specialization students in Malaysia from two higher education institutions: a public university (PU) and a teacher training institute (TTI). The two skills investigated to study the 127 participants were communication skills and leadership skills. From the total number, 77 participants were from the PU and the remaining 50 from the TTI. The MyGSI instrument was employed to measure the skills and data were analyzed and reported into mean value. The findings suggested an acceptable account of mastery among the trainee teachers in both skills even though a higher proficiency was evident among the PU students. The study implicated 1) a further in-depth research on the syllabus of these institutions as to how the results were not at variance, 2) an effort for a standardization of an improved syllabus to encourage the production of excellent teachers across schools in Malaysia, and 3) a portfolio assessment among the students where the display of generic skills through program participation and management by the trainee teachers is graded officially by the training institutions.
\end{abstract}

Keywords: generic skills, communication and leadership, higher education, Malaysian teacher training

\section{Introduction}

Generic skills are part of the essentials for a person to function efficiently and holistically in everyday life and these skills have been addressed extensively at all levels of formal education in Malaysia especially the higher education. Generic skills are not only limited to the skills related to the subject matters in a student's major (Lizzio \& Wilson, 2004), but rather, they include communication skills, teamwork skills, and problem-solving skills (Biggs, 1999) among others. In order to produce a generation of students with a great set of generic skills, teachers should be able to integrate the elements that encourage the development of these skills during the teaching and learning process. Thus, as a guide to school teachers, the Curriculum Development Center (1995) listed the skills that must be possessed by students for the purpose of career preparation, namely skills in: 1) communication, 2) technology and numerical application, 3) planning and administration, 4) teamwork, 5) problem-solving and decision-making, and 6) cross-cultural understanding. Naturally, it is imperative that these skills be mastered by trainee teachers in their training period in order to serve as effective future agents of socialization in the community. Apart from the prerequisite subject content mastery, the trainee teachers should also be acquainted with as many generic skills as possible to meet the requirement in the national education syllabus.

Quality teachers are not beyond reach, but will require significant investments. Some are naturally born with the appropriate pedagogical skills while others are willing to strive hard to develop these skills in them. Their roles are of crucial importance to ensure that the national agenda of progressing towards a developed country is achieved by the year 2020. This is evident in the Malaysian Education Blueprint 2006-2010 which expounded the role of education in developing knowledgeable and highly skilled individuals with good values to successfully achieve Vision 2020. Thus, this research attempted to investigate the level of generic skills among a group of future teachers in a public university (PU) and a teaching training institute (TTI) that focused on two aspects, namely communication, and leadership.

\section{Problem Statement}

The higher education institutions are the key players to foster the growth of the society, especially in 
empowering Malaysia as a knowledge-based developed country. Their roles transcend the traditional responsibility from merely expanding and promoting the culture of knowledge towards fulfilling the national aspiration and expectations. This shift aims at producing outstanding students who are creative and innovative and rational thinkers with high self-discipline and moral values (Dickerson \& Green, 2004; Hogarth \& Wilson, 2005) in response to the national agenda of education (Hashamiza, 2004; Mohd Izham, 2011). Nevertheless, recent public concern that questions the declining credibility of the students from the current education system, particularly in terms of leadership and self-worthiness, deserves a serious attention. The likely factor that has led to this turmoil is the inclination towards the sole mastery subject matter of their study major while overlooking self-improvement related to value-added skills. The Ministry of Higher Education (MoHE) and the Ministry of Human Resources reported an alarming unemployment rate; 11 reasons had been identified and seven of which were in relation to the shortcomings of generic skills. Thus, a Module of Human Skills Development was introduced in 2006. With this module, the MoHE had enforced its implementation across almost all curricular and co-curricular courses at all higher education institutions in the country.

The many public perceptions regarding the poor student standard have prompted important questions as to whether the higher education institutions are indeed preparing all the necessary knowledge and training necessary generic skills for these future teachers. These issues gave impetus to this research as it set out to compare and measure two sets of generic skills among the trainee teachers of the Malay language specialization. In addition, similar studies that involved this cohort of participants are yet to be found as most of them have been mainly concerned with teachers from the technical and vocational stream.

Basing on the premise that the duty to instil generic skills falls mainly on teachers with a background in communication, the research decided to choose trainee teachers from the language field as participants of the research. Their teaching content, after all, is related to communication to a great extent as opposed to other technical subjects such as science, information technology and engineering that prioritize on the subject matter. Thus, the research decided to compare one Malaysian public university (PU) with one teaching training institute (TTI), involving third-year students of the Malay language specialization.

\section{Research Questions}

This comparative research was conducted to examine and compare the levels of generic skills of the trainee teachers in a PU and TTI to answer this question:

1) What are the level of Malay language option trainee teachers' generic skills in terms of the communication skills and leadership skills?

\section{Methodology}

\subsection{Research Design}

This research was a quantitative research that applied the Malaysian Generic Skills Inventory (MyGSi) instrument. The quantitative research design was chosen because of its nature that explains a certain phenomenon and measurements numerically. The items were analyzed using the Rasch model to determine the trustworthiness and the authenticity of the MySGi construction.

\subsection{Research Participants}

This research was conducted involving two cohorts of trainee teachers from the program of Bachelor of Education in the Teaching of Malay Language in one PU and one TTI in Malaysia. A total of 127 participants of the third-years were randomly chosen as the research participants. The number is higher than 100 as a sample size with less than the number is not reliable because there will be a big fluctuation in calculations, especially when the research is replicated (Chua Yan Piaw, 2006).

\subsection{Research Instrument}

The instrument used by the researchers in this research was a set of Malaysian Generic Skill Inventory (MySGi) questionnaire, developed by a group of researchers in Universiti Kebangsaan Malaysia (Siti Rahayah, 2003). Using the Likert scale to measure the skills of communication and leadership among the trainee teachers, each item requested the participants to state their level of agreement, ranging from "strongly disagree (1)" to "strongly agree (5)". The questionnaire contained 81 items and consisted of two parts: Section A and Section B. The first section contained a list of questions to collect the demographics of the participants involving the information about their major of study, year of study, work experience and their Cumulative Grade Point Average. The second section comprised three constructs of generic skills viz. communication, leadership and group work and each construct led to many subconstructs. However, only the findings from Section B covering two constructs of 
generic skills (communication and leadership skills) were reported in this paper.

\subsection{Data Analysis}

A detailed review of the survey was performed with a computerized analysis using the Statistical Packages for the Social Science (SPSS) version 11.5 to extract data. The analysis of the result was arranged into a table to show the mean and discussion from the cumulative readings was presented separately according to each construction.

\section{Results and Findings}

\subsection{Construct 1: Communication Skills}

As indicated in Table 5.1, the participants from both groups displayed a high set of communication skill, which was evident by high mean values for most items in the communication subconstruct. The mean average for each communication subconstruct exceeded 3.67 except for the use of non-verbal skills (mean=3.499). Scholars claimed that a mean average greater than 3.67 indicates that the items in a certain construct have a high reliability (Alias, 1993; Chua Yan Piaw, 2006).

The average mean of the communication skills based on the 8 items were in the range between 3.499 and 3.907. The highest mean was in the ability to deliver a presentation with a mean of 3.907. The lowest mean was for the subconstruct on the ability of using non-verbal skills with the mean of 3.499. The remaining subconstructs were high: the ability to summarize (3.896), to practice listening skills (3.887), to negotiate (3.848), to interact (3.799), to present an idea verbally (3.787), and finally, the ability to present an idea in written form (3.701). The average mean for the communication skills as shown by the trainee teachers in the study was 3.791 .

The highest mean of the participants from the PU was in the ability to make a presentation (4.14), followed by the ability to practice listening skills (4.12), to negotiate (4.01), to interact (4.00), to summarize (3.97), to present an idea verbally (3.96), and to present an idea in written form (3.87).

The participants from the TTI showed the highest ability to interact with a mean of 3.81 , followed by the ability to make a presentation and ability to negotiate (both 3.72 ) and the ability to practice listening skills (3.70). The remaining subconstructs were not as impressive; their ability to present an idea verbally recorded a mean of 3.64, the ability to summarize (3.66), and the ability to present an idea in written form (3.57).

The data suggested that the participants from the PU surpassed their counterparts from the TTI in every subconstruct except one - the ability to use nonverbal skills with an equal mean of 3.50 . This turned out to be the lowest mean for both groups.

Table 1. Mean average for the communication subconstructs

\begin{tabular}{llcccc}
\hline \multirow{2}{*}{ No. } & \multicolumn{2}{c}{ Subconstruct } & \multicolumn{3}{c}{ Mean average } \\
& & PU & TTI & Total \\
\hline 1 & Ability to use nonverbal skills & 3.50 & 3.50 & 3.499 \\
2 & Ability to practice listening skills & 4.12 & 3.70 & 3.887 \\
3 & Ability to present an idea verbally & 3.96 & 3.64 & 3.787 \\
4 & Ability to present an idea in written form & 3.87 & 3.57 & 3.701 \\
5 & Ability to deliver a presentation & 4.14 & 3.72 & 3.907 \\
6 & Ability to negotiate & 4.01 & 3.72 & 3.848 \\
7 & Ability to interact & 4.00 & 3.81 & 3.799 \\
8 & Ability to summarize & 3.97 & 3.66 & 3.896 \\
& & & & & 3.791 \\
\hline
\end{tabular}

\subsection{Construct 2: Leadership Skills}

The analysis indicated that the participants had a high mean average i.e. above 3.67 for all the subconstructs under the leadership aspect. The ability to consider differing opinions were of the highest mean (4.03), followed by the ability to lead group members to an agreement and the skill to identify and develop potential (both 3.94), the ability to plan and manage and the ability to make proper decisions (both 3.92). They were identified to be 
less skilful in the ability to accept responsibility and the ability to complete multi-dimensional tasks (both 3.91) and finally the ability to give instructions (3.83). The overall mean was 3.925 which fell into the high category.

On a comparative term, the participants from the PU were found to be surpassing their counterparts in all the 8 subconstructs. The trainee teachers from the PU displayed the highest mean in the ability to consider differing opinions (4.23). The second highest mean from the PU trainees was on the ability of identifying and developing potential (4.19) and the third highest was in the ability to make proper decisions (4.09) and this was followed by the ability to plan and manage as well as the ability to complete multi-dimensional tasks (both 4.08) and the ability to accept responsibility and the ability to lead group members to an agreement (both 4.06). The lowest mean from the trainees of the PU was 3.98 in the ability to give instructions.

Interestingly, the highest mean of the trainees from the TTI was also the ability to consider differing opinions (3.87). The second highest mean was the ability to lead group members to an agreement (3.84). Meanwhile, the third highest mean was the ability to accept responsibility and the ability to plan and manage (both 3.79 ). The fourth and the fifth highest mean, with a slight difference, were the ability to make proper decisions (3.78) and the ability to complete multi-dimensional tasks (3.77). These were followed by the ability to identify and develop potential with a mean of 3.74 and finally the ability to give instructions with a mean of 3.70 .

Table 2. Mean average for the leadership skill subconstructs

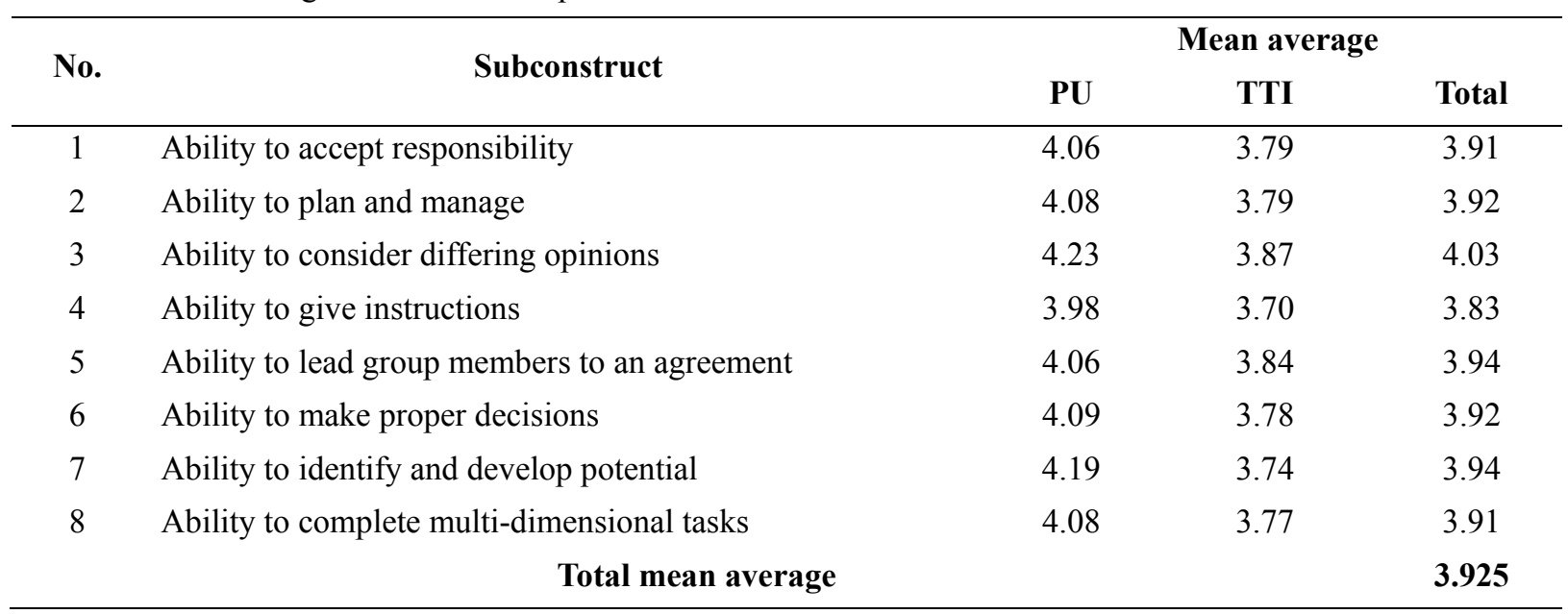

\section{Discussion of Result}

There had been a significant display of competence in most of the subconstructs across the communication and leadership skills as suggested by the mean value that ranged from 3.50 to 4.19 . The revelation is promising as the participants are future teachers who are expected to nurture and instil these skills among school students in Malaysia. Mastering these skills is thus prerequisite to enculturation among their future students. However, there are several issues that need to be addressed as reflected by the findings in order to improve the teaching practice at the Malaysian level.

The results suggested that the trainees from the PU surpassed their counterparts in every section but one subconstruct, indicating that either they had been receiving good training at the university. In other words, the syllabus and its execution at the PU have been effective. A second interpretation could have been that the training provided was similar between the two institutions but by some means the participants in the PU had managed to accommodate to the training better than their counterparts. In response to this possibility, a further in-depth research on the syllabus of these institutions as to how the results were not at variance needs to be conducted. An effort for a standardization of the syllabus should also be an emphasis to encourage the production of excellent trainee teachers regardless of their higher education institutions.

In terms of the communication aspect, the overall mean average of the communication subconstructs was found to be lower as compared to the leadership. However, the mean was still considered high with the trainee teachers from the PU displaying a greater mastery in all subconstructs except one. This is a good indicator because communication is pivotal in a teacher's career as he or she needs to communicate with a great number of stakeholders especially with the students. More importantly, the communication needs to be effective. Weak 
communication will jeopardize the teaching and learning process by complicating the process of deciphering messages or in a worse scenario, the messages might be wrongly interpreted. A situation as such is not impossible if the students keep their confusion to themselves when dealing with teachers with ineffective communication skills.

To overcome this challenge, the academicians in the teacher training institutions of Malaysia are advised to encourage the trainee teachers to be more vocal during discussions in the lectures, tutorials and student presentations. This might appear to be of significant challenge because Asians, due to cultural inhibition, often refuse to express a conflicting opinion so as to save face or to appear friendly in front of the others. However, it is a timely call that Malaysian students need to be taught to be outspoken in a subtle and non-threatening manner. An attempt towards that objective can be achieved by blending outspokenness with humility; voicing an opinion honestly but with a respectful tone and choice of words is the best policy to exhibit courtesy.

Considering the current trend among the youth of the country, this effort will not be impossible. Due to the borderless world, they have been exposed to the different cultures of the rest part of the world, particularly the Western countries through the mass media in the form of print, electronic or New Age media. This has led them to be more culturally enlightened and expressive in voicing out their opinions. Exposing the society to different cultures of the world with an appropriate amount of censorship is one of the efforts by the government in educating the people on racial harmony and integrity. The heterogeneity of race at the institutions with students from different ethnicity, demographic background, and social economic status serve to train the participants to tolerate various types of people in their lives and to encourage the socialization process. Thus, it was not surprising when they displayed a high mean for the ability to interact, a crucial skill considering the fact that Malaysia is composed of many different ethnicities.

However, from the eight subconstructs which involved both the receptive as well as expressive skills, the participants were good except for the non-verbal communication subconstruct which was low among the trainees from both groups. This is alarming as a Malaysian-based research conducted by Jamaluddin (2009) suggested that verbal remarks guaranteed only 10 percent of the effectiveness in the classroom communication process, whereas the remaining 90 percent remained in the application of non-verbal skills such as the facial expressions, eye contact, body gestures, and voice tone.

The second generic skill investigated in this study - the leadership skill - promises a successful mastery across all eight sub-constructs among the trainee teachers. Leadership skills are essential for teachers who are constantly engaged in classroom management, apart from leading and managing school activities. These are the skills that are closely related to the communication skills as the integration of good communication skill reflects the leadership ability as well as the ability of supporting, consulting, settling conflicts, solving problem and producing a healthy relationship (Nurul Afizah, 2005).

The trainees were recognized to be multi-tasking leaders who were able to take responsibility, execute plans and manage them by taking into account the different views of group members, recognize and develop their potential to lead to the most appropriate decision-making process. There is a probability that this competence is partly due to the system introduced at the students' residential colleges which requires them to be actively involved as organizers of student programs. Conducting a portfolio assessment among the students is thus advisable to involve all students where the display of generic skills through program participation and management by the trainee teachers is graded officially.

Another potential contributory factor that has led to a group of multi-taskers is the fact that the students have been trained with many different assignments in their courses that demanded them to present, write term paper and group assignment, and conduct mock teaching sessions as well as creative projects that requires them to interview, act, or dance. These various types of assignments have undoubtedly played a major role in enhancing the students' versatility. Working in a team for an assignment demanded that the students build a good rapport with each other. This was evident by the high level of respect as indicated by their ability to attend to differing views.

The indication of good leadership skills suggests that the participants were trainee teachers with a good discerning emotion quotient (EQ), a claim made based on the research by Goleman (1996) that reported a higher leadership performance in social and personal efficiency, emotion management, and self-independence among participants with a high EQ score. A high EQ can create a successful individual in interpersonal and intrapersonal relationships and thus, it can be safely assumed that the participants in the research would serve the teaching community well as leaders to the school and to their future students. 


\section{Conclusion}

The role of effective institutions of higher learning needs to transcend the mere effort of producing graduates with intellectual capabilities because the graduates need to be nurtured with generic skills to assist them in career and especially to function well in life. Developing generic skills successfully lies in the skilful nurturing by experienced teachers in an effective classroom. A good teacher-oriented lesson may produce students who are good with theories, but may also produce passive and dependent students who are afraid to take charge.

Scholars in past studies have identified that the methods of contributing ideas, presentation, acting, and self-research are the contributing means towards the development of generic skills. Thus, this research was conducted to investigate the current level of generic skills among the trainee teachers in the aspects of communication and leadership. The findings indicated a positive representation of the participants' skills as future teachers in Malaysian secondary schools and this is a good indicator that they will be able to acquaint their future students with the much needed skills. As Malaysian studies involving the Malay language specialization trainee teachers are scarce in number, it is highly recommended that further investigation be conducted to examine other most equally important sets of generic skills among the trainee teachers.

\section{References}

Adnan, N. A. (2005). Perkaitan Profil Kemahiran Generik Aliran Teknikal di Politeknik Malaysia (Unpublished master's dissertation). Kolej Universiti Teknologi Tun Hussein Onn, Johor.

Ariffin, S. R. (2003). Teori, Konsep dan Amalan dalam Pengukuran dan Penilaian. Bangi: Penerbit Universiti Kebangsaan Malaysia.

Baba, A. (1993). Statistik Penyelidikan dalam Pendidikan dan Sains Sosial. Bangi: Penerbit Universiti Kebangsaan Malaysia.

Biggs, J. (1999). Teaching for Quality Learning at University. Birmingham: Open University Press.

Curriculum Development Center. (1995). Generic skills. Kuala Lumpur: Ministry of Education Malaysia.

Dickerson, A. P., \& Green, F. (2004). The Growth and Valuation of Computing and other Generic Skills. Oxford Economic Papers, 56(3), 371-406. http://dx.doi.org/10.1093/oep/gpf049

Goleman, D. (1996). Emotional intelligence: Why it can matter more than IQ? London: Bloomsbury Publishing Plc.

Hamdan, H. (2004). Pengintegrasian Aspek-aspek Kemahiran Generik Dalam Proses P\&P Program Kemahiran Tinggi: Satu Kajian Kes di Pusat Latihan Teknologi Tinggi (ADTEC) dari Perspektif Pengajar. (Unpublished master's dissertation). Kolej Universiti Teknologi Tun Hussein Onn, Johor.

Hamzah, M. I. M. (2011). Analisis keperluan majikan terhadap kemahiran generik bagi pembangunan modal insan. In Z. Mahamod, J. L. A. Wahab, \& M. S. Ibrahim (Eds.), Transformasi dan Inovasi dalam Pendidikan (pp. 449-662). Bangi: Fakulti Pendidikan, Universiti Kebangsaan Malaysia.

Hogarth, T., \& Wilson, R. (2005). The Demand for Skills in England: Volume 2 - Research Report. Learning and Skills Council (LSC).

Lizzio, A., \& Wilson, K. (2004). First Year Students' Perception of Capability. Research in Higher Education, 29, $109-126$.

Piaw, C. Y. (2006). Research Methods. Shah Alam: McGraw-Hill Education.

\section{Copyrights}

Copyright for this article is retained by the author(s), with first publication rights granted to the journal.

This is an open-access article distributed under the terms and conditions of the Creative Commons Attribution license (http://creativecommons.org/licenses/by/3.0/). 